\title{
Enhancement of Load Frequency Control Concerning High Penetration of Wind Turbine using PSO-Fuzzy Technique
}

\author{
Neethu John \\ PG Scholar \\ Vivekanandha College Of Engineering for women \\ Tiruchengode,Tamil nadu. India
}

\author{
K Remesh \\ Assistant Professor \\ Vivekanandha College Of Engineering for women \\ Tiruchengode,Tamil nadu. India
}

\begin{abstract}
Due to rapidly growing amount of wind turbines and new types of power generation and demand technologies, The infrastructure Load Frequency Control (LFC) in power system should improve. Maintenance of frequency of power system is done by Automatic Load Frequency Control (AGC). Since the complexity of power systems are increasing, now days LFC systems must be able to handle multi-objective regulation optimization problems and capable to maintain generationload balance, during serious disturbances. Unlike other renewable energy sources wind power fluctuations impose additional power disturbances to the power system and cause frequency variations from the desired value. This paper addresses a PSO based fuzzy logic controller LFC schemes for the minimization of both frequency deviation and tie-line power changes, necessary for successful operation of interconnected power systems during of high-penetration wind power. The particle swarm optimization (PSO) technique is used to get optimal values of membership functions parameters. Demonstrate effectiveness of the proposed control scheme, a time domain simulation is performed on the standard bus test system using MATLAB/SIMULINK
\end{abstract}

\section{General words}

Wind turbines,Load Frequency Control,Automatic Generation Control

\section{Keywords}

Load frequency Control (LFC), Fuzzy Controller, Particle Swarm Optimization(PSO), Wind turbines, Automatic Frequency Control(AGC)

\section{INTRODUCTION}

The increasing need for electrical energy as well as limited fossil fuel reserves, very high transportation and fuel cost and the increasing concerns with environmental issues for the reduction of carbon dioxide and other greenhouse gases causes fast development in the area of renewable energy sources (RESs). RESs are derived from natural sources such as the sun, wind, hydro-power, biomass, geothermal, oceans and fuel cells that replenished themselves over a relatively short period of time. The most kind of the RES used is wind energy which is clean and available in nature. They are generally less problematic than those from other power sources. Therefore, the distributed generations, especially wind power generations attract attentions in many countries. As of 2011, 83 countries around the world are using wind power on a commercial basis. As of 2010 wind energy was over $2.5 \%$ of total worldwide electricity usage, growing at more than $25 \%$ per annum

As the use of wind power turbines increases worldwide, there is a rising interest on their impacts on power system operation and control .Regarding the nature of wind power variation, the impact on the frequency regulation issue has attracted increasing research interest, during the last decade. The primary energy source (wind) cannot be stored and is uncontrollable, the controllability and availability of wind power significantly differs from conventional power generation. In most power systems, the output power of wind turbine generators varies with wind speed fluctuation, this fluctuation results into frequency variation and tie line power changes, here comes the need for Load Frequency Control(LFC)/Automatic Frequency Control(AGC).

\section{AN OVERVIEW ON LOAD FREQUENCY CONTROL}

Christie et.al(1995) discussed about load frequency control issues after deregulation where the simple frequency control become a challenging issue due to this competitive environment. The paper identified deregulation scenarios; technical Issues associated with load frequency control, and identify technical solutions, such as standards and algorithms.

A.M Stankovic et.al (1998) addresses the analysis and design issues in Load Frequency Control (LFC) for a power system participates in interconnection. This gives a effective closed-loop control on the bases of Quantitative feedback theory .That provides convenient graphical tools for design and analysis methods for two system interconnected model. George Gross et.al (2001) presents development and application of an analytic framework based on NERC criteria CPS1 and CPS2.The frame work provided a solid analytic basis for formulation, analysis and evaluation of LFC criteria.In the case of RESs, H. Bevrani et.al(2010) gave overview of the key issues and new challenges on frequency regulation concerning the integration of renewable energy units into the power systems. Power system frequency response in the presence of RESs and associated issues is analyzed, and the need for the revising of frequency performance standards is emphasized.

A non-linear time- domain simulation study considering a standard 39-bus and 24-bus test systems. Johan Morren et.al (2006) discussed about Wind Turbines Emulating Inertia and Supporting Primary Frequency Control. The increasing penetration of wind turbines require changes in the way in which the grid frequency is controlled. In paper a method was suggested such that variable-speed wind turbines are able to support primary frequency control and to emulate inertia by 
applying additional control loops. Ronan Doherty et.al (2010) discussed about the inertial characteristics associated with turbine technology during high penetration. Doubly fed induction generators and high-voltage dc interconnection alter the frequency behavior significantly. The analysis in this paper applied extensive time series dispatch sampling, recorded historical wind turbine operating characteristics, and simplified dynamic simulation models to investigate the effects of changing plant portfolios on system frequency control Time-series sampling studies such as applied.

In order to overcome problems in LFC the methods proposed in past decades includes control system design concepts, LFC scheme based on classical concepts, LFC schemes based on modern concepts which includes optimal LFC schemes and Intelligent LFC schemes.

\section{LOAD FREQUENCY CONTROL (LFC)}

The LFC is to control the frequency deviation by maintaining the real power balance in the system. The main functions of the LFC are to i) to maintain the steady frequency ii) control the tie-line flows; and iii) distribute the load among the participating generating units. The control (input) signals are the tie-line deviation $\Delta \mathrm{P}_{\text {tie }}$ (measured from the tie line flows), and the frequency deviation $\Delta \mathrm{f}$ (obtained by measuring the angle deviation. These error signals $\Delta \mathrm{f}$ and $\Delta \mathrm{P}_{\text {tie }}$ are amplified, mixed and transformed to a real power signal, which then controls the valve position. Depending on the valve position, the turbine (prime mover) changes its output power to establish the real power balance. The governors of all the machines sense the frequency and the mechanical power outputs will be changed automatically to match the combined generation with the new combined load. This action is called primary regulation. But frequency remains at a new value and set points must be adjusted, just as in single machine case for frequency restoration. This job is done by Load Frequency controller (LFC). This process of set point adjustment is called secondary regulation.

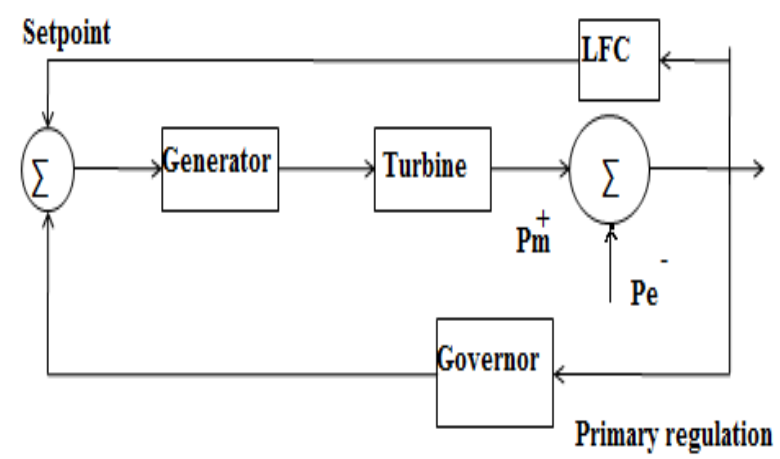

Figure 1 block diagram of governing system

As in figure 1 when load change occurs frequency varies and the regulation initially for the first few seconds is due to the action of the governors of all generating units and subsequently the Load frequency control system prevails.

\section{CONVENTIOAL METHOD OF LFC}

To generalize the conventional model, the updated Area Control Error (ACE) signal should represent the impacts of wind power on the scheduled flow over the tie-lines. The
ACE signal is traditionally defined as a linear combination of frequency and tie-line power changes as follows

$$
A C E=\beta \Delta f+\Delta P_{\text {tie }}
$$

Where

The $\Delta \mathrm{f}$ is frequency deviation, the $\beta$ frequency bias and $\Delta$ Ptie is difference between the actual (act) and scheduled (sched) .Power flows for a given area with $\mathrm{m}$ tie-lines as follows

$$
\Delta P_{\text {tie }}=\sum_{i=1}^{m}\left(P_{\text {tie, act } j}-P_{\text {tie,shed } j}\right)
$$

For a considerable amount of wind (W) power, its impact must be also considered with conventional $(C)$ power flow in the overall area tie-line power. Therefore, the updated $\Delta \mathrm{P}_{\text {tie }}$ can be expressed as follows

$$
\begin{gathered}
\Delta P_{\text {tie }}=\Delta P_{\text {tie-C }}+\Delta P_{\text {tie-W }} \\
\Delta P_{\text {tie }}=\sum_{j=1}^{m}\left(P_{\text {tie-C,act } j}-P_{\text {tie-C.shed } j}\right.
\end{gathered}
$$

Using equations (3.1) and (3.3), an updated ACE signal can be completed as follows

$$
\begin{aligned}
A C E= & \beta \Delta f+\sum_{i=1}^{m}\left(P_{\text {tie-C }, \text { act } j}-P_{\text {tie-C }, \text { shed } j}\right) \\
& +\sum_{j=1}^{m}\left(P_{\text {tie-W,act } j}-P_{\text {tie-W,estim } j}\right)
\end{aligned}
$$

Where $\mathrm{P}_{\text {tie }-\mathrm{C} \text { act }}, \mathrm{P}_{\text {tie-c }}$, sched, $\mathrm{P}_{\text {tie-W,act }}$, and $\mathrm{P}_{\text {tie-W }}$, estim are actual conventional tie-line power, scheduled conventional tie line power, actual wind tie-line power, and scheduled wind tie-line power, respectively. The conventional LFC designs are usually suitable for working at specific operating points, and they are not more efficient for modern power systems, considering increasing size, changing structure, emerging renewable energy sources, and new uncertainties. Most of conventional LFC synthesis methodologies provide model-based controllers that are difficult to use for large-scale power systems with nonlinearities, and uncertain parameters it is expected that using intelligent LFC schemes in new environment to be more adaptive/flexible than conventional ones, and is going to become an appealing approach Recently, following the advent of modern intelligent methods, such as artificial neural networks, fuzzy logic, multi agent systems, genetic algorithms, expert systems, simulated annealing, tabu search, ant colony optimization, and hybrid intelligent techniques, some new potentials and powerful solutions for LFC synthesis have arisen.

\section{FUZZY LOGIC CONTROLLER}

The fuzzy logic because of simplicity, and reliability is used in solving a wide range of problems in power system control and operation., some differing from each other by the type of inputs and outputs, or less significantly by the number and type of input and output fuzzy sets and their membership functions. The basic blocks in fuzzy logic controller are Fuzzification block, Inference mechanism, Knowledge base and Defuzzification block 
Crisp input information (usually measured ACE or frequency deviation) from the control area is converted into fuzzy values for each input fuzzy set with the fuzzification block. The inference mechanism determines how the fuzzy logic operations are performed, and together with the knowledge base determine the outputs of each fuzzy IF-THEN rules. Those are combined and converted to crispy values with the defuzzification block. The output crisp value can be calculated by the center of gravity or the weighted average; then, the scaled output as control signal is applied to the generating units. Here MAMDANI type fuzzy controller were used.

Fuzzification dealing with uncertain information, which might be objective or subjective in nature. The fuzzification block in the fuzzy controller represents the process of making crisp quantity into fuzzy. In fact, the fuzzifier converts the crisp input to a linguistic variable using the membership functions stored in the fuzzy knowledge base. Fuzziness in a fuzzy set is characterized by the membership functions. Using suitable membership functions, the ranges of input and output variables are assigned with linguistic variables. These variables transform the numerical values of the input of the fuzzy controller to fuzzy quantities.

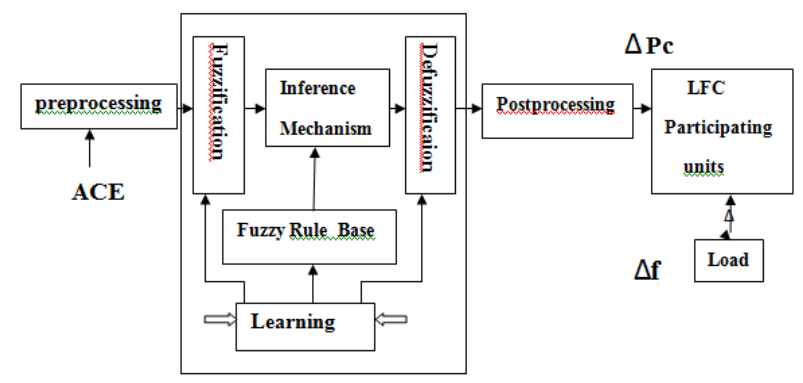

Figure2 Fuzzy controller

These linguistic variables specify the quality of the control. Triangular, trapezoid, and Gaussian are more common membership functions to use in fuzzy control systems. Knowledge rule base consists of information storage for linguistic variables definitions and fuzzy rules. The concepts associated with a database are used to characterize fuzzy control rules and a fuzzy data manipulation in fuzzy logic controller. A lookup table is made based on discrete universes that defines the output of a controller for all possible combinations of the input signals. A fuzzy system is characterized by a set of linguistic statements in the form of "IF-THEN" rules. Fuzzy conditional statements make the rules or the rule set of the fuzzy controller. The inference engine uses the IF-THEN rules to convert the fuzzy input to the fuzzy output.Defuzzifier converts the fuzzy output of the inference engine to crisp using membership functions analogous to the ones used by the fuzzifier. For the defuzzification process, commonly center of sums, meanmax, weighted average and centroid methods are employed. Algorithm of fuzzy controller as follows:

A controller design based on fuzzy logic for a dynamical system involves the following four main steps.

Step 1: Understanding of the system dynamic behavior and characteristics. Define the states and input/output control variables and their variation ranges.
Step 2: Identify appropriate fuzzy sets and membership functions.Create the degree of fuzzy membership function for each input/output variable and complete fuzzification.

Step 3: Define a suitable inference engine. Construct the fuzzy rule base, using the control rules that the system will operate under. Decide how the action will be executed by assigning strengths to the rules.

Step 4: Determine defuzzification method. Combine the rules and defuzzify the output.

The ACE and its derivative are usually chosen as inputs of the fuzzy controller. These two signals are then used as ruleantecedent (IF-part) in the formation of rule base, and the control output is used to represent the contents of the rule consequent (THEN-part) in performing of rule base. Normalization or scale transformation which maps the physical values of the current system state variables into a normalized universe of discourse should be properly considered. This action is also needed to map the normalized value of control Output variables into its physical domain (denormalization output). The normalization can be obtained by dividing each crisp input on the upper boundary value for the associated universe.

\section{PARTICLE SWARM OPTIMAZTION}

The PSO is a population-based stochastic optimization technique. It belongs to the class of direct search methods that can be used to find a solution to an optimization problem in a search space. The PSO originally based on social behavior of bird flocking, fish schooling, and swarming theory. A swarm consists of a set of individuals, with each individual specified by position and velocity vectors $(x i(t), v i(t))$ at each time or iteration. Each individual is named as a particle and the position of every particle represents a potential solution to the under study optimization problem. In an $n$-dimensional solution space, each particle is treated as a $n$-dimensional space vector and the position of the $i$ th particle is presented by $\mathrm{vi}=\left(\mathrm{x}_{\mathrm{il}}, \mathrm{x}_{\mathrm{i} 2}, \ldots, \mathrm{x}_{\mathrm{i} 3}\right)$; then it flies to a new position by velocity represented by $\mathrm{v}=\left(\mathrm{v}_{\mathrm{i} 1}, \mathrm{v}_{\mathrm{i} 2}, \ldots, \mathrm{v}_{\mathrm{in}}\right)$.

The best position for $i$ th particle represented by $\mathrm{P}_{\text {best }} \mathrm{i}=\left(\mathrm{P}_{\text {bes }}\right.$ $\left.{ }_{i 1}, \mathrm{P}_{\text {best }{ }_{\mathrm{i} 2}}, \ldots, \mathrm{P}_{\text {best in }}\right)$ is determined according to the best value for the specified objective function. Furthermore, the best position found by all particles in the population (global best position), can be represented as $\mathrm{g}_{\text {best }}=\left(\mathrm{g}_{\text {best } 1}, \mathrm{~g}_{\text {best } 2}, \ldots\right.$, $\left.\mathrm{g}_{\text {best } \mathrm{n}}\right)$. In each step, the best particle position, global position, and the corresponding objective function values should be saved. For the next iteration, the position $x_{i k}$ and velocity $v_{i k}$ corresponding to the kth dimension of ith particle can be updated using equations as follows;

$$
\begin{aligned}
v_{i k}(t+1)= & w \cdot v_{i k}+C_{1} \cdot \operatorname{rand}_{1, i k}\left(P_{b e s t, i k}(t)-x_{i k}(t)\right) \\
& +C_{2} \cdot \operatorname{rand}_{2 . i k}\left(g_{b e s t, k}(t)-x_{i k}(t)\right)
\end{aligned}
$$

$x_{i k}(t+1)=x_{i k}(t)+v_{i k}(t+1)$

where

$$
\mathrm{i}=1,2, \ldots, n \text { is the index of particle }
$$




\section{$\mathrm{w}$ is The inertia weight}

rand $_{1, \mathrm{ik}}$ and $\mathrm{rand}_{2, \mathrm{ik}}$ are random numbers in the interval $[0$ 1], $\mathrm{c} 1$ and $\mathrm{c} 2$ are learning factors, $\mathrm{t}$ is number of iterations. The steps for PSO as follows:

Step 1: All particles are initialized via a random solution. In this step, each particle position and associated velocity are set by randomly generated vectors. Dimension of position should be generated within a specified interval, and the dimension of velocity vector should be also generated from a bounded domain using uniform distributions.

Step 2: Compute the objective function for the particles.

Step 3: Compare the value of the objective function for the present position of each particle with the value of objective function corresponding to pre specified best position, and replace pre specified best position by the present position, if it provides a better result.

Step 4: Compare the value of the objective function for the present best position with the value of the objective function corresponding to global best position, and replace present best position by the global best position, if it provides a better result.

Step 5: Update the position and velocity of each particle according to (6.1) and (6.2).

Step 6: Stop algorithm if the stop criterion is satisfied. Otherwise, go to step 2. Otherwise go to step 2.

The PSO algorithm is used to find the optimal value for membership function parameter of fuzzy logic based LFC system.

\section{PSO BASED FUZZY LOGIC CONTROLLER}

To provide an adaptive and self-tuning fuzzy logic-based LFC system, the parameters of fuzzy logic controller (membership functions) can be adjusted using an external tuning mechanism as shown in the figure 3 In this case, the adaptive fuzzy controller has a distinct architecture consisting of two loops: an inner control loop, which is the basic feedback loop, and an outer loop, which adjusts the parameters of the controller. Here, the PSO technique is used to perform the mentioned tuning mechanism.In each control area, the PSO technique is used for tuning of fuzzy system's membership function parameters in the supplementary frequency control loop to improve the overall control performance. The control framework is shown in figure 4 .

\section{PSO BASED FUZZY LOGIC CONTROLLER ON WIND TURBINES}

Increasing in size and complexity of power systems as well as emerging wind turbines an their effects on dynamic behavior of power system, caused conventional LFC systems [Proportional-Integral (PI) controllers] be incapable of providing good dynamical performance over a wide range of operating condition. To get a desirable LFC performance in the presence of high penetration wind power in a multi area power system, a decentralized pso-based fuzzy logic control design is considered. The inputs and output are brought into an acceptable range by multiplying in proper gains. In each control area, ACE and its derivative are considered as input signals, and the provided control signal is used to change the set points of LFC participant generating units. The Mamdanitype inference system is applied. Symmetric 7-segments triangular membership functions are used for input (a) and output (b) variables as shown in figure 5(a)\&5(b).

The membership functions are defined as zero (ZO), large negative $(\mathrm{LN})$, medium negative $(\mathrm{MN})$, small negative $(\mathrm{SN})$, small positive (SP), medium positive (MP), and large positive (LP).In this work, in order to reach fast response from the controller system, all membership functions considered as triangular with the mathematical definition as follows:

$\mu_{x}\left(x_{i}\right)=\max \left(0,1-\left|\frac{x-x_{i}}{c}\right|\right)$

where $\mathrm{x}$ and $\mathrm{c}$ are the mean and spread of the fuzzy set $\mathrm{X}$, respectively xi is a crisp variable. Fuzzy rule base fuzzy rule is the basis of fuzzy logic operation to map input space to the output space. The rule base works on vectors composed of ACE and its gradient dACE. Using Table I, fuzzy rules can be expressed in the form of IF-THEN statements such as:

\section{IF ACE is SN AND dACE is MP, THEN output is SN}

In the above IF-THEN statement, the antecedent part of the rules is composed of two parts, combined with fuzzy AND operators. The combination is done based on interpreting the AND operator by algebraic Product operation. Considering equation (7) the antecedent part of above statement may be defined as follow

$\mu_{(A C E A N D \text { dACE })}(x, y)=\mu_{(A C E)}(x) \cdot \mu_{(d A C E)}(y)$

where $\mu$ (ACE AND dACE) is the membership value of the antecedent part, and $\mu \mathrm{ACE}$ and $\mu \mathrm{dACE}$ are the membership values of ACE and dACE, respectively. Similarly, for computing the consequent of each rule, the membership function of "Mamdani Product" implication method can be represented by

$$
\mu_{M P}(x, y)=\mu_{(A C E A N D d A C E)} \cdot \mu_{\triangle P_{C}}
$$

where

$\mu_{\mathrm{MP}}$ is the membership function resulted by Mamdani Product implication and $\mu$ (ACE AND dACE) is membership value of the related antecedent part.

Since fuzzy rules are stated in terms of linguistic variables, crisp inputs should be also mapped to linguistic values using fuzzification. In order to combine rules and make a decision based on all the rules, the sum method is used. Finally, for converting output fuzzy set of the fuzzy system to a crisp value, the centroid method is used for defuzzication.

As it can be seen in Figure 5(a) each set of input membership functions can be specified by parameters $a$ and $b$, where min < $\mathrm{a}<\mathrm{b}<\max$. Also, for control output, one parameter is needed to be specified. Therefore, five parameters should be optimized for inputs membership functions using PSO algorithm are $a_{\text {in,ACE }}, b_{\text {in,ACE }}, a$ in,dACE,$b_{\text {in,dACE}}$, and bout. For the PSO algorithm used the objective function $(f)$ is considered as given in equation (8.4). 


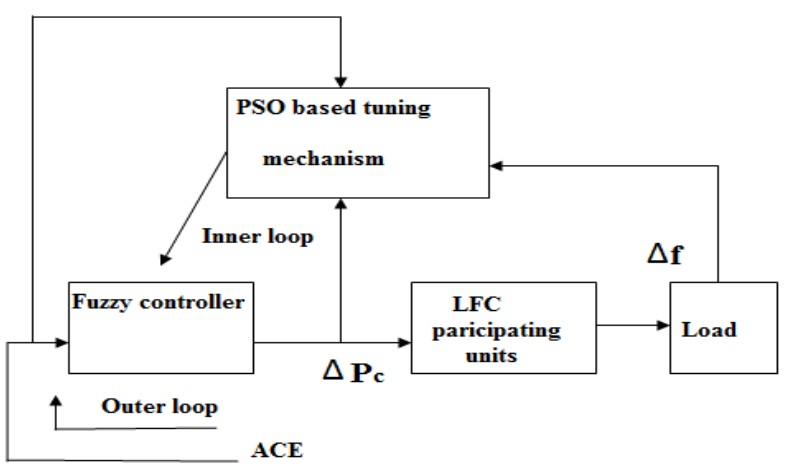

Figure 3 PSO based fuzzy controller

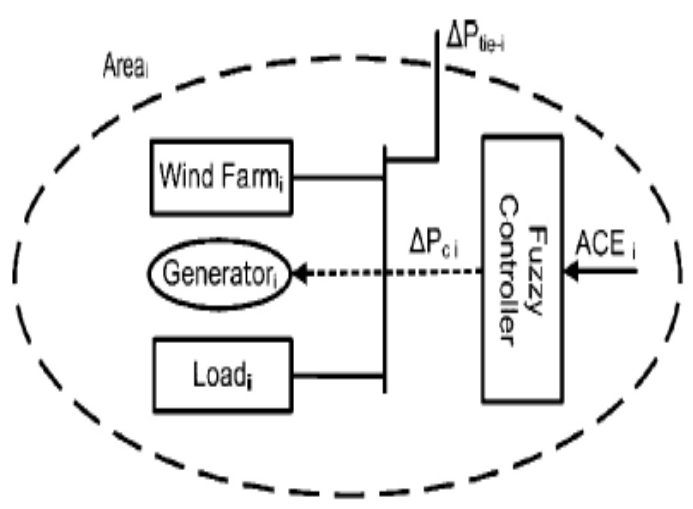

Figure 4 frame work of control

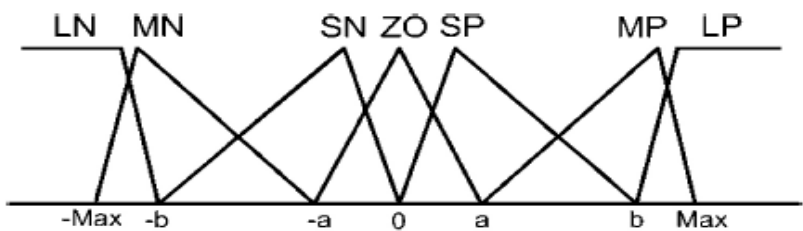

(a)

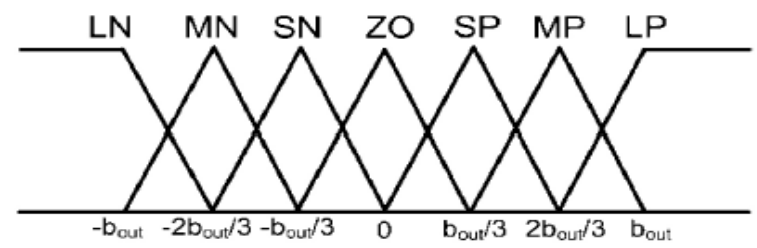

(b)

Figure5 (a) input membership function 5(b) output membership function

As the performance of a fuzzy system is influenced by the membership functions, in order to achieve good performance by the controller, a PSO algorithm is established to find the optimal value for membership functions parameters and exact tuning of them. As it can be seen in Figure 4.4, each set of input membership functions can be specified by parameters a and $b$, where $\min <a<b<\max$. Also, for control output, one parameter is needed to be specified. Therefore, five parameters should be optimized for inputs membership functions using PSO algorithm are $a_{\text {in, ACE }}, b_{\text {in, ACE }}, a_{\text {in,dACE}}$, $\mathrm{b}_{\mathrm{in}, \mathrm{dACE}}$, and bout. For the PSO algorithm used the objective function $(f)$ is considered as given in equation (10).

$$
f=\frac{1}{3} \sum_{i=1}^{3}\left(\int t\left(\left|f_{i}\right|+\left|\Delta P_{t i e, i}\right|\right) d t\right.
$$

In effective LFC scheme with a desirable performance in the presence of high penetration of wind turbines; therefore, the case study is updated by adding a wind farm to each control area. All wind farms are composed of a number of more popular type of wind turbines, i.e., DFIG.For the sake of simulation, random variations of wind velocity have been considered. All power plants in the power system are equipped with speed governor and power system stabilizer.

Figure 7 shows a schematic block diagram which represents the decentralized fuzzy logic-based control structure for the considered power system having 3 area to be controlled. As it can be seen in Figure 7 only one generator in each area is responsible for the LFC task The controllers are responsible for producing appropriate control actions $(\triangle \mathrm{Pc})$ according to the measured ACEs and their time derivatives (dACE).

To investigate the performance of PSO based fuzzy logic LFC scheme a 9 bus system is considered. This testing system is used for studying the effectiveness of LFC scheme due to presence of high penetration of wind turbine. By LFC scheme 3 areas are controlled, in which in one area one generator will be controlled



Figure 6 Decentralized controlling structure for multiarea

\section{SIMULATION RESULTS}

The PSO algorithm is used to optimize the membership function of fuzzt logic controller the output from PSO is as shown below

xbest $=$

$\begin{array}{lllll}0.5100 & 0.7000 & 0.2300 & 0.5000 & 2.0000\end{array}$

Above values are the input to the fuzzy controller and output of the controller will fed to valblock in the simulink model, which is controlling variable for trip signal in the plant. 


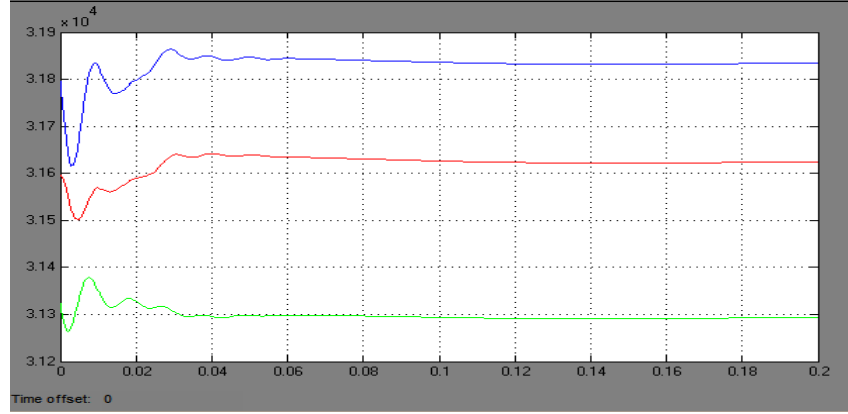

Figure 7 waveforms of ACE for three control areas

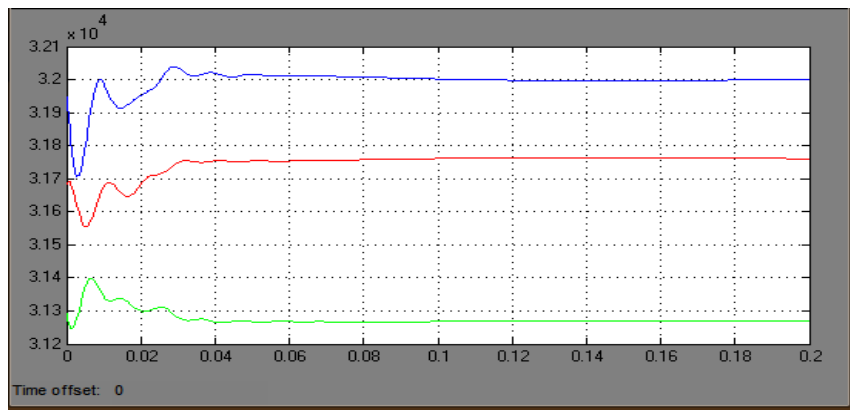

Figure 8 waveforms of variation in frequency for three control areas

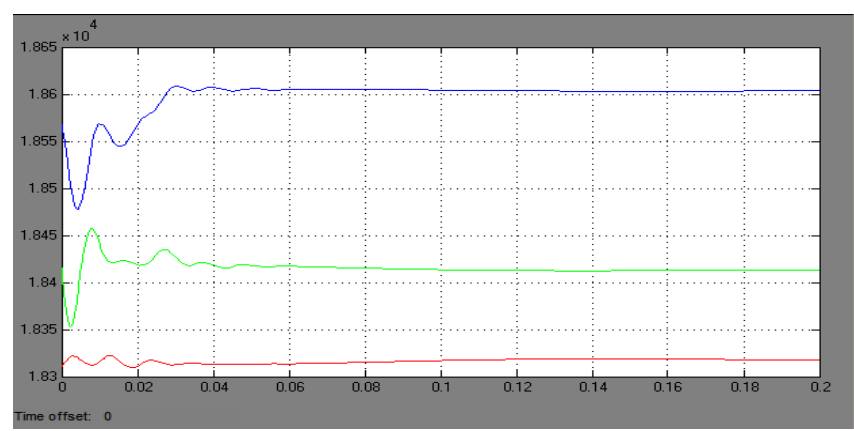

Figure 8 waveforms of variation in power for three control areas

\section{CONCLUSIONS AND DISCUSSION}

An adaptive PSO based fuzzy logic structure is considered for intelligent LFC scheme in the interconnected large-scale power systems in the presence of wind turbines. The PSO technique was applied to adjust fuzzy control parameters. Here multi area control, three wind farms in different areas are controlled.PSO is used to optimize the membership function of fuzzy to get optimized output. The method was examined on 9 bus, including wind farms. The simulation results demonstrated that the considered intelligent LFC scheme provides desirable performance against sudden load change and wind power fluctuations in different wind power penetration rates. It will improve the frequency deviation and output power variation in tie line power. In future to improve the LFC genetic algorithm and colony algorithm with fuzzyPID controller can be used. The waveforms of ACE, frequency deviation and power deviation can be compare with PSO based fuzzy logic controller. The result will tested on MATLAB/SIMULINK.

\section{REFERENCES}

[1] Abdel-Magid Y.L., and Dawoud M.L. (1995) 'Genetic algorithms applications in load frequency control,' Proc.IEE Conference publication No. 414, Shetheld, U.K., pp.207-212.

[2] BevraniH. (2009) 'Robust power system frequency control,'1st edn.Springer, Heidelberg

[3] Bevrani H., Daneshfar F., and Daneshmand.R . (2010) 'Intelligent power system frequency regulation concerning the integration of wind power units inWind Power Systems,': Application of Computational Intelligence,Kusiak,Eds.Heidelberg,Germany:SpringerVerlag, pp.407-437.

[4] Bevrani H., Ghosh A., and Ledwich. (2010) 'Renewable energy sources and frequency regulation: Survey and new perspectives,' IET Renew. Power Gener., Vol. 4, No. 5, pp. 438-457.

[5] Bevrani, H., and Hiyama T. (2009) 'On load-frequency regulation with time delays: design and real-time implementation,' IEEE Transaction on Energy Conversion Vol24, No.1, pp.292-300.

[6] Bevrani H., and Hiyama T. (2007) 'Robust loadfrequency regulation: a real-time laboratory experiment,'Optimal Control Appl. Methods 28, pp.419433.

[7] Birch A.P., Sapeluk C.S., and Ozveren C.S. (1994) 'Enhanced neural network load frequency control technique,' Proc. International Conf. on Control, Coventry, U.K , pp. 409-415.

[8] Busoniu L., Babuska, R.., De Schutter B. (2008) 'A comprehensive survey of multiagent reinforcement learning'. IEEE Transaction on Syst., Man.Cyber Part C: Application sand Reviews Vol.38, No.2, pp.156-172.

[9] Cavin III R.K., Budge Jr M.C., and Rasmussen P. (1971) 'An optimal linear systems approach to load frequency control,' IEEE Trans on Power Apparatus and Systems, PAS-90, pp. 2472-2482.

[10] Chang C.S., and Weihui Fu. (1997)‘Area load frequency control using fuzzy gain scheduling of PI controllers,' Electric Power Systems Research, Vol.42, pp. 145-152.

[11] Chedid R.B., Karaki S., and El-Chamali C. (2000) 'Adaptive fuzzy control for wind diesel weak power systems,'IEEE Transaction Energy Conversion, Vol. 15, No. 1, pp. 71-78.

[12] Dokopoulos A., Saramourtsis C., and Bakirtzis A.G. (1996) 'Prediction and evaluation of the performance of wind-diesel energy systems,'IEEE Transaction Energy Conversion, Vol. 11, No. 2, pp. 385-393.

[13] Eberhart R., and Kennedy J. (1995) 'A new optimizer using particle swarm theory,'in Proc. 6th Int.Symp. Micro Mach. Human Sci., pp 39-43.

[14] El-Sherbiny M. K., El-Saady G., and Ali M. Yousef. (2002) 'Efficient fuzzy logic load frequency controller Energy Conversion and Management,'Vol. 43, pp. 1853 1863. 
[15] Feliachi A. (1987) 'Optimal decentralized load frequency control,' IEEE Transaction, Power Apparatus and Systems, Vol.PWRs-2, No.2,pp. 379-385.

[16] Ganesh V.,Vasu K., and Bhavana P. (2012) 'LQR Based Load Frequency Controller for Two Area Power System,' International Journal of Advanced Research in Electrical, Electronics and Instrumentation Engineering Vol.1, No 4,pp.262-269.

[17] George Gross., and Jeong Woo Lee. (2001) 'Analysis of Load Frequency Control performance Assessment Criteria,' IEEE Transactions on power systems Vol.16, No.3,pp 520-525.

[18] Ha Q.A. and Trinh H. (2000)'A variable structure based controller with fuzzy tuning for load frequency control,' International Journal of power and energy systems, Vol.20, No.3,pp.146-154.

[19] Ha Q.P. (1998) 'A fuzzy sliding mode controller for power system load frequency control' in Proc. second international conference on knowledge based intelligent electronic systems, pp.149-154.

[21] Hassan Bevrani., and Pourya Ranjbar Daneshmand. (2012) 'Fuzzy Logic-Based Load-Frequency Control Concerning High Penetration of Wind Turbines,' IEEE systems journal, Vol.6, No.1,pp.173-180.

[22] Hiyama T., (1982) 'Optimization of discrete-type loadfrequency regulators considering generation rate constraints,' Proc. IEE, 129(C), pp.285- 289.

[24] Hiyama T., Esaki H, and Funabashi T. (2005) 'Experimental studies on multiagent based AGC for isolated power system with dispersed power sources',Eng. Intell. Syst., Vol. 13, No. 2, pp. 135-140.

[25]Experimental studies on multiagent based AGC for isolated power system with dispersed power sources

[26] Jawad Talaq and Fadel Al-Basri, (1999) 'Adaptive fuzzy gain scheduling for load-frequency control,' IEEE Transactions on Power Systems,Vol.14, No. 1,pp.145150

[27] Lalor G., Mullane A., and Malley M.O, (2005) 'Frequency control and wind turbine technologies,'
IEEE Transaction Power Syst.,Vol. 20,No. 4, pp.19051913.

[28] Mohamed M., Ismail M.A., and Mustafa Hassan. (2012) 'Load Frequency Control Adaptation Using Artificial Intelligent Techniques for One and Two Different Areas Power System,' International journal of control, automation and systems Vol.1, No.1,pp.12-23.

[29] Morren J., De Haan S.W.H., Kling W.H, and Ferreira W.A (2006) 'Wind turbines emulating inertia and supporting primary frequency control.' IEEE Transaction Power Syst.Vol.21,No.1,pp. 433-434.

[30] Mostafa El., Mokadem., Vincent Courtecuisse., Christophe Saudemont., Benoit Robyns. and Jacques Deuse. (2009) 'Fuzzy Logic Supervisor-Based Primary Frequency Control Experiments of a Variable-Speed Wind Generator,' IEEE Transactions on power systems, Vol.24, No.1,pp.407-417.

[31] Nakamura M. and Hatazaki H. (1977) 'A new loadfrequency control system based on optimal control theory,' Electrical Engineering in Japan, Vol.97, No. 4, pp.32-40.

[32] Ronan Doherty., Alan Mullane., Gillian Lalor Nolan., Daniel J. Burke., Alexander Bryson. and Mark O'Malley. (2009) 'An Assessment of the Impact of Wind Generation on System Frequency Control,' IEEE Transactions on power systems, Vol. 25, No. 1,pp.452460.

[34] Sabahi1K., Nekoui1M.A., Teshnehlab M., Aliyari M. and Missouri M (2007) 'Load Frequency Control in Interconnected Power System Using Modified Dynamic Neural Network,' Proceedings of $15^{\text {th }}$ Mediterranean conference on control automation, Athens-Greece pp.243-250.

[35] Willems J.L. (1974) 'Sensitivity analysis of the optimum performance of conventional load frequency control,' IEEE Transaction Power Apparatus and Systems, PAS (93), No. 5, pp. 1287-1291. 38. Yesil E., Guzelkaya M. and Eksin I. (2004) 'Self tuning fuzzy PID type load and frequency controller,' Energy Conversion and Management, Vol.45,No.3, pp. 377-390 